\title{
A method for predicting the alkali concentrations in pore solution of hydrated slag cement paste
}

\author{
W. Chen · H. J. H. Brouwers
}

Received: 13 November 2010/Accepted: 12 January 2011/Published online: 25 January 2011

(C) The Author(s) 2011. This article is published with open access at Springerlink.com

\begin{abstract}
The alkalinity of the pore liquid in hardened cement paste or concrete is important for the long-term evaluation of alkali-silica reaction (ASR) expansion and corrosion prevention of steel bar in steel reinforced structures among others. It influences the reactivity of supplementary cementitious materials as well. This paper focuses on the alkali binding in hydrated slag cement paste and a method for predicting the alkali concentrations in the pore solution is developed. The hydration of slag cement is simulated with a computer-based model CEMHYD3D. The amount of alkalis released by the cement hydration, quantities of hydration products, and volume of the pore solution are calculated from the model outputs. A large set of experimental results reported in different literatures are used to derive the alkali-binding capacities of the hydration products and practical models are proposed based on the computation results. It was found that the hydrotalcite-like phase is a major binder of alkalis in hydrated slag cement paste, and the $\mathrm{C}-\mathrm{S}-\mathrm{H}$ has weaker alkali-binding capacity than the $\mathrm{C}-\mathrm{S}-\mathrm{H}$ in hydrated Portland cement paste. The method for predicting the alkali concentrations in the pore solution of hydrated slag cement paste is used to investigate the effects of different factors on the alkalinity of pore solution in hydrated slag cement paste.
\end{abstract}

\footnotetext{
W. Chen $(\square)$

School of Materials Science and Engineering, Wuhan University of Technology, Luoshi Road 122, 430070 Wuhan,

People's Republic of China

e-mail: w.chen.whut@gmail.com

\section{H. J. H. Brouwers}

Department of Architecture, Building and Planning,

Eindhoven University of Technology, P.O. Box 513,

5600 MB Eindhoven, The Netherlands

e-mail: jos.brouwers@tue.nl
}

\section{Introduction}

The pore fluid in hardened cement paste and concrete contains remarkable amounts of ions and is thus called pore solution. The concentrations of alkali ions in the pore solution are important for the durability of concrete and passivation of the protective film on the steel bars in the reinforced structures. The alkalinity of the pore solution in hardened concrete influences the reactivity of supplementary cementitious materials such as fly ash and as well. Therefore, knowledge on the development of the alkali concentrations helps to select the proper materials and to evaluate the long-term performance of the hardened concrete.

Most research on the development of alkali concentrations in the pore solution of hardened cement pastes or concrete is based on the expression method developed by Longuet et al. [1]. The liquid is squeezed out of the samples and the ion concentrations are analyzed. This method requires complex facilities and special care to minimize the environmental effect. Obtaining long-term results in a fairly short period is also difficult because there are no reliable techniques for speeding up the hydration process of cement paste [2]. Prediction of the long-term development of the alkali concentrations in the pore solution of hardened cement paste or concrete will therefore be useful since most durability problems occur in a long term.

Taylor proposed a method for predicting the alkali concentrations in the pore solution of hydrated Portland cement paste [2]. An alkali partition theory was proposed according to which parts of the alkalis released by the cement hydration are bound in the hydration products and the others are in the pore solution. This method was taken over by Brouwers and Van Eijk [3] with parameters such as the hydration degree of cement, amounts of alkalis and 
hydration products, and the volume of pore solution calculated from the outputs of a computer-based cement hydration model CEMHYD3D [4].

Replacing Portland cement with slag reduces the alkalinity of the pore solution remarkably [5, 6], of which the mechanisms are not completely revealed. The $\mathrm{C}-\mathrm{S}-\mathrm{H}$ gel in hydrated slag cement pastes has remarkably lower calcium to silicate $(\mathrm{C} / \mathrm{S})$ ratios than that in Portland cement paste and incorporates more aluminum in its structure [7], which probably possesses enhanced alkali-binding capacities [8-10].

However, the alkali binding in the other hydration products like the hydrotalcite-like phase could also contribute to the reduction effect. Formation of syngenite and the "U-phase" (a sodium-substituted AFm phase) probably occur in cement pastes with very high alkali contents, or immersed in water with high alkali concentrations. This situation is hardly encountered in conventional cement pastes.

The main focus of this research is to investigate the alkali-binding capacities of hydration products in slag cement paste by using the alkali partition theory proposed by Taylor [2] and to extend the computer-based model by Brouwers and van Eijk [3] for predicting the alkali concentrations in pore solution of hydrating slag cement paste. The quantities of alkalis released by the slag cement hydration, the volume of pore solution, and the quantities of the solid hydration products in the hydrated slag cement paste are predicted with the model for the slag cement hydration established by Chen and Brouwers [11]. The alkali-binding capacities of the hydration products such as the $\mathrm{C}-\mathrm{S}-\mathrm{H}$ gel and the hydrotalcite-like phase are derived from a large set of measurements reported in different literatures and models for these binding capacities are established. The extended method is used to investigate the effects of various factors such as the compositions of the binders (cement and slag), the water to binder ratio and the reactivity of slag on the alkali concentrations of the pore solution.

\section{Alkali partition in hydrated slag cement paste}

The alkali partition theory originally developed by Taylor is firstly introduced with considerations to the hydration of slag and clinker [2]. The slag proportion in the cement $(\lambda)$ is defined as

$\lambda=\frac{m^{\mathrm{sl}}}{m}=\frac{m^{\mathrm{sl}}}{m^{\mathrm{p}}+m^{\mathrm{sl}}}$

in which $m$ is the mass of the slag cement; $m^{\mathrm{p}}$ is the mass of the Portland clinker and $m^{\text {sl }}$ is the mass of slag. The moles of alkali ions $\left(\mathrm{Na}^{+}\right.$or $\left.\mathrm{K}^{+}\right)$in the clinker and slag are calculated with Eqs. 2 and 3, respectively.
$n_{i}^{\mathrm{T}, \mathrm{p}}=\frac{2 x_{i}^{\mathrm{p}}}{M_{i}} \cdot m^{\mathrm{p}}=\frac{2 x_{i}^{\mathrm{p}}}{M_{i}} \cdot m \cdot(1-\lambda)$

$n_{i}^{\mathrm{T}, \mathrm{sl}}=\frac{2 x_{i}^{\mathrm{sl}}}{M_{i}} \cdot m^{\mathrm{sl}}=\frac{2 x_{i}^{\mathrm{sl}}}{M_{i}} \cdot m \cdot \lambda$

in which $n_{i}^{\mathrm{T}, \mathrm{p}}$ and $n_{i}^{\mathrm{T}, \mathrm{sl}}$ are the total moles of alkali ion $i$ in the Portland cement and slag, respectively; $x_{i}^{\mathrm{p}}$ and $x_{i}^{\mathrm{sl}}$ are the mass fraction of alkali oxides in Portland cement and slag, respectively; $M_{i}$ is the molar mass of the oxide $i\left(\mathrm{Na}_{2} \mathrm{O}\right.$ or $\left.\mathrm{K}_{2} \mathrm{O}\right)$.

The moles of alkalis released by the clinker hydration are calculated as

$n_{i}^{\mathrm{r}}=n_{i}^{\text {sul }}+n_{i}^{\mathrm{r}, \text { clinker }}=\left[f_{i}^{\text {sul }}+\sum f_{i, j} \cdot\left(1-f_{i}^{\text {sul }}\right) \alpha_{j}\right] \cdot n_{i}^{\mathrm{T}, \mathrm{p}}$

in which $n_{i}^{\text {sul }}$ is the mole of alkali ions present as sulfates and $n_{r}^{\text {clinker }}$ is the mole of alkalis in the solid solution form in clinker; $f_{i, j}$ is the mass fraction of alkali $i$ in the clinker phase $j ; \alpha_{j}$ is the hydration degree of clinker phase $j$. The same method as used by Taylor [2] for determining $f_{i}^{\text {sul }}$ and $f_{i, j}$ is followed.

The moles of alkalis released by the slag hydration are calculated as

$n_{i}^{\mathrm{r}, \mathrm{sl}}=\alpha^{\mathrm{sl}} \cdot n_{i}^{\mathrm{T}, \mathrm{sl}}$

in which $\alpha^{\text {sl }}$ is the hydration degree of slag. The alkali in slag is released proportionally to the slag reaction degree whereas the alkali in clinker is partially released instantaneously and partially upon hydration. The total moles of alkalis released by the slag cement hydration are calculated as

$$
\begin{aligned}
n_{i}^{\mathrm{r}} & =n_{i}^{\mathrm{r}, \mathrm{sl}}+n_{i}^{\mathrm{r}, \mathrm{p}=} \\
& =\left[f_{i}^{\mathrm{sul}}+\sum f_{i, j} \cdot\left(1-f_{i}^{\mathrm{sul}}\right) \alpha_{j}\right] \cdot n_{i}^{\mathrm{T}, \mathrm{p}}+\alpha^{\mathrm{sl}} \cdot n_{i}^{\mathrm{T}, \mathrm{sl}}
\end{aligned}
$$

The released alkalis are known to be partitioned in the pore solution and in the hydration products. Therefore,

$n_{i}^{\mathrm{r}}=n_{i}^{\mathrm{b}}+n_{i}^{\mathrm{s}}$

in which $n_{i}^{\mathrm{b}}$ is the moles of alkalis bound in products; $n_{i}^{\mathrm{s}}$ is the moles in the solution. The moles of alkalis in the solution are calculated as:

$n_{i}^{\mathrm{s}}=C_{i} \cdot V_{w}$

in which $C_{i}$ is the concentration of alkali ion $i(\mathrm{~mol} / \mathrm{L}) ; V_{w}$ is the volume of pore solution (L). Substituting Eq. 8 into Eq. 7 gives:

$n_{i}^{\mathrm{r}}=n_{i}^{\mathrm{b}}+C_{i} \cdot V_{w}$

$n_{i}^{\mathrm{r}}$ and $V_{w}$ in Eq. 9 can be predicted with empirical equations as used by Taylor [2], or with computer models for Portland cement hydration as used by Brouwers and 
Van Eijk [3]. In Eq. 6, the hydration degrees of the clinker phases and the slag are required for computing the moles of alkalis released by the slag cement hydration $\left(n_{i}^{\mathrm{r}}\right)$ and also the volume of the pore solution $\left(V_{w}\right)$.

The slag and Portland clinker in slag cement normally hydrate at different rates, resulting in different hydration degrees at the same age. While the computer model CEMHYD3D can be used to predict the hydration degrees of the clinker phases as used by Brouwers and Van Eijk [3], it cannot predict the hydration degree of slag, yet.

In this study, a method of combining both empirical equations and computer modeling is used. The hydration degrees of clinker phases are simulated with the CEMHYD3D [4], which is proven to be a useful tool for modeling the hydration of Portland cement already [12, 13]. The hydration rate of slag is predicted with an empirical method similar to that used by Taylor [2] for clinker hydration, with further considerations on the different reactivity of slag.

The computer model CEMHYD3D is a pixel-based digital model, which can simulate the hydration process and the microstructure development of hydrating Portland cement pastes. Details of this computer model were given by Bentz [4, 12]. It is used in this study to predict the hydration degree of the clinker phases $\left(\alpha_{j}\right)$.

The reaction degree of slag in the blended cement is predicted with the following equation:

$\alpha^{\mathrm{sl}}=1-\exp \left[-k_{2}\left(t / 24-k_{3}\right)^{k_{1}}\right]$

in which $k_{1}, k_{2}$, and $k_{3}$ are three characteristic factors (dimensionless), $t$ is the hydration time (in h). Values of $k_{1}$, $k_{2}$, and $k_{3}$ for predicting the hydration degree of belite in clinker used by Taylor [2] are taken to be valid for the slag reaction as well (Table 1).

A linear relationship between the hydration degree of slag and the slag proportion in cement was observed in experiments (Fig. 1) [6]. Therefore, Eq. 10 is further corrected for the slag proportions in cement as

$\alpha^{\mathrm{sl}}=\left\{1-\exp \left[-k_{2}\left(t / 24-k_{3}\right)^{k_{1}}\right]\right\} \cdot\left(a^{\mathrm{sl}} \cdot \lambda+b^{\mathrm{sl}}\right)$

in which $a^{\mathrm{sl}}$ and $b^{\mathrm{sl}}$ are the two characteristic coefficients of the linear relationship. A linear regression analysis with the experimental data by Schäfer [6] yields the values for $a^{\text {sl }}$ and $b^{\text {sl }}$ as included in Table 1. The predicted hydration degree of slag with Eq. (11) is plotted in Fig. 2. It can be

Table 1 Factors for predicting the hydration degree of slag

\begin{tabular}{lllll}
\hline$k_{1}$ & $k_{2}$ & $k_{3}$ & $a^{\mathrm{sl}}$ & $b^{\mathrm{sl}}$ \\
\hline 0.46 & 0.12 & 0 & -0.0036 & 0.86 \\
\hline
\end{tabular}

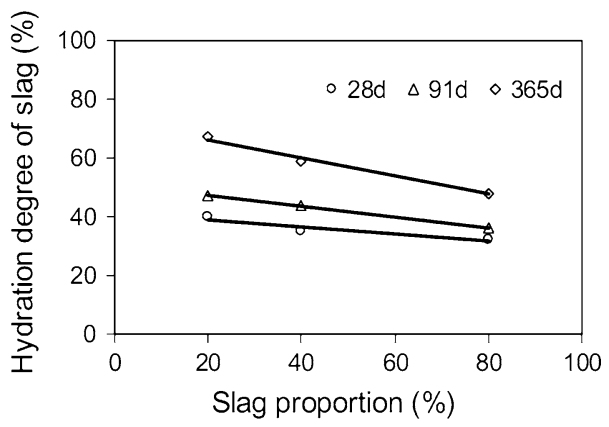

Fig. 1 Hydration degree of slag in cement pastes with different slag proportions $\left(w / c=0.5, T=20^{\circ} \mathrm{C}\right)$. Symbols measurements by Schäfer [6]; solid lines trend line

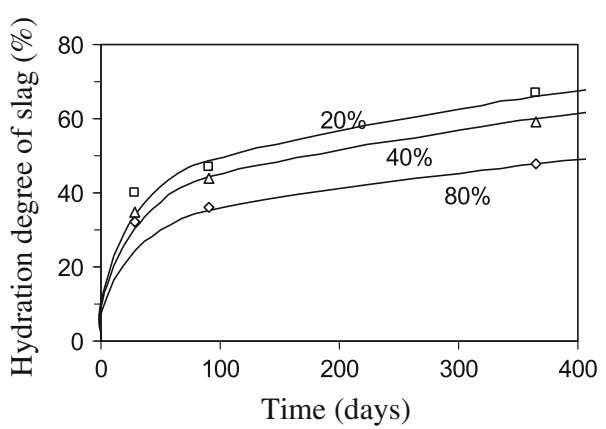

Fig. 2 Predicted and measured hydration degree of slag in cement pastes with different slag proportions $\left(w / c=0.5, T=20^{\circ} \mathrm{C}\right)$. Symbols measurements by Schäfer [6]; solid lines predictions

concluded that Eq. 11 is appropriate for predicting the reaction degree of slag in blended cement.

The outputs of the CEMHYD3D for clinker hydration and Eq. 11 are used as inputs for the theoretical models developed by Chen and Brouwers [11] to predict the amounts of the hydration products, their compositions, and the volume of pore solution in the hydrated slag cement paste.

\section{Alkali binding in hydration products}

The amount of alkalis bound in the hydration products is affected by factors such as the type of products, their quantities, and their alkali-binding capacities. The main hydration products in hydrated slag cement pastes are the C-S-H gel, a hydrotalcite-like phase, ettringite, a Fe-containing hydrogarnet phase, portlandite, and some AFm phases [14]. Among these products, the ettringite and portlandite normally exist in the crystalline form and the alkali-binding capacities of them are negligible. The Fe-containing hydrogarnet phase and the AFm phases are quantitatively minor. Therefore, it is most likely that $\mathrm{C}-\mathrm{S}-\mathrm{H}$ and the hydrotalcite-like phases are the main alkalibinding products. 
Table 2 Oxide composition of clinker and slag used in the experiments of Longuet [5] and Schäfer [6] (m/m\%)

\begin{tabular}{|c|c|c|c|c|c|c|c|c|c|c|}
\hline \multirow[t]{2}{*}{ Oxide } & \multicolumn{3}{|c|}{ Clinker } & \multicolumn{7}{|l|}{ Slag } \\
\hline & $\mathrm{C}^{\mathrm{a}}$ & $\mathrm{C} 2^{\mathrm{b}}$ & $\mathrm{C} 3^{\mathrm{b}}$ & $\mathrm{S} 1^{\mathrm{a}}$ & $\mathrm{S} 2^{\mathrm{a}}$ & $S 3^{\mathrm{a}}$ & $\mathrm{S} 4^{\mathrm{a}}$ & $\mathrm{S} 5^{\mathrm{b}}$ & $S 6^{\mathrm{b}}$ & $S 7^{\mathrm{b}}$ \\
\hline $\mathrm{SiO}_{2}$ & 21.36 & 21.05 & 20.69 & 35.16 & 31.64 & 36.06 & 33.43 & 34.6 & 30.37 & 38.52 \\
\hline $\mathrm{Al}_{2} \mathrm{O}_{3}$ & 5.36 & 5.99 & 5.64 & 11.86 & 17.39 & 12.16 & 14.8 & 12.05 & 16.1 & 9.49 \\
\hline $\mathrm{TiO}_{2}$ & 0.32 & 0.3 & 0.23 & 0.41 & 0.59 & 0.58 & 0.74 & 0.62 & 1.14 & 0.97 \\
\hline $\mathrm{P}_{2} \mathrm{O}_{5}$ & 0.12 & 0.12 & 0.08 & 0.15 & 0.16 & 0.1 & 0.08 & 0.01 & 0.02 & 0.02 \\
\hline $\mathrm{Fe}_{2} \mathrm{O}_{3}$ & 3.26 & 2.88 & 3.17 & 1.2 & 1.4 & 0.71 & 1.13 & 0.58 & 1.25 & 1.6 \\
\hline $\mathrm{MnO}$ & 0.06 & 0.07 & 0.04 & 0.82 & 0.37 & 0.68 & 1.18 & 0.28 & 0.4 & 1.24 \\
\hline $\mathrm{CaO}$ & 62.58 & 65.83 & 66.15 & 44.68 & 44.17 & 39.72 & 38.48 & 42.58 & 38.02 & 36.79 \\
\hline $\mathrm{MgO}$ & 5.03 & 1.54 & 1.47 & 4.31 & 4.53 & 7.8 & 8.2 & 7.54 & 10.25 & 8.49 \\
\hline $\mathrm{SO}_{3}$ & 0.35 & 0.88 & 0.91 & 0 & 0 & 0 & 0 & 0.01 & 0.53 & 0.01 \\
\hline $\mathrm{K}_{2} \mathrm{O}$ & 1.27 & 0.95 & 1.22 & 0.22 & 0.76 & 1.13 & 1.08 & 0.38 & 0.39 & 1.25 \\
\hline $\mathrm{Na}_{2} \mathrm{O}$ & 0.25 & 0.14 & 0.19 & 0.2 & 0.31 & 0.6 & 0.73 & 0.29 & 0.41 & 0.41 \\
\hline
\end{tabular}

a Longuet [5]

b Schäfer [6]

The structure of the hydrotalcite-like phase is similar to a family of inorganic materials known as layer double hydroxides (LDH). It has a layered crystal structure composed of hydroxide layers and interlayer containing anions and water molecules. The hydrotalcite-like phase is known for its large specific area and high anion-exchange capacities, which is able to absorb large amount of anions [15].

The alkali-binding capacities of the hydration products (the $\mathrm{C}-\mathrm{S}-\mathrm{H}$ gel and the hydrotalcite-like phase) in hydrated slag cement paste are derived from the experimental measurements as following.

Define the molality of alkali $i$ in the hydration product as $M a_{i}$. Then, the total amount bound in the product reads

$n_{i}^{\mathrm{b}}=M a_{i} \cdot m^{\mathrm{hp}}$

in which $m^{\text {hp }}$ is the mass of the hydration product. Equation 9 is then rewritten as

$n_{i}^{\mathrm{r}}=M a_{i} \cdot m^{\mathrm{hp}}+C_{i} \cdot V_{w}$

The alkali-binding capacity of the hydration product $\left(M a_{i}\right)$ is calculated as

$M a_{i}=\frac{n_{i}^{\mathrm{r}}-C_{i} \cdot V_{w}}{m^{\mathrm{hp}}}$

The values of $n_{i}^{\mathrm{r}}, m^{\text {hp }}$, and $V_{w}$ can be predicted with the hydration models for slag cement hydration established by Chen and Brouwers [11]. Therefore, the value of $M a_{i}$ is calculated if the alkali concentration in the pore solution is known.

A large set of experimental data reported in different literatures $[5,6]$ are used for deriving the alkali-binding capacities of the hydration products in hydrated slag cement paste. The chemical composition of the pore solution in hydrated slag cement paste mixed with different
Table 3 Recipes of slag cement used in the experiments of Longuet [5] and Schäfer [6]

\begin{tabular}{llll}
\hline Num. & Recipe & Num. & Recipe \\
\hline 1 & C1-S1-75 & 10 & C2-S5-40 \\
2 & C1-S1-75 & 11 & C2-S5-80 \\
3 & C1-S2-75 & 12 & C2-S6-40 \\
4 & C1-S2-75 & 13 & C2-S6-80 \\
5 & C1-S3-75 & 14 & C2-S7-40 \\
6 & $\mathrm{C} 1-S 3-75^{\mathrm{b}}$ & 15 & C2-S7-80 \\
7 & $\mathrm{C} 1-\mathrm{S} 4-75^{\mathrm{a}}$ & 16 & $\mathrm{C} 3-\mathrm{S} 5-40$ \\
8 & $\mathrm{C} 1-\mathrm{S} 4-75^{\mathrm{b}}$ & 17 & $\mathrm{C} 3-\mathrm{S} 6-40$ \\
9 & $\mathrm{C} 2-\mathrm{S} 5-20$ & 18 & $\mathrm{C} 3-\mathrm{S} 7-40$ \\
\hline
\end{tabular}

a $4.5 \mathrm{~m} / \mathrm{m} \%$ gypsum added

b $8.6 \mathrm{~m} / \mathrm{m} \%$ gypsum added

slag and clinker was measured. The chemical compositions of clinker and slag used in the experiments are listed in Table 2. The recipes of the slag-blended cement are listed in Table 3. The pastes were all prepared with a $w / c$ ratio of 0.5 and cured at $20{ }^{\circ} \mathrm{C}$ up to 2 years. The pore solutions were expressed out of the paste at different ages and the ion concentrations were analyzed.

The hydration of Portland clinker in the pastes as listed in Table 3 is simulated with the computer model CEMHYD3D and the hydration degree of slag is predicted with Eq. 11. The reaction model for the slag-blended cement proposed by Chen and Brouwers [11], which allows the interaction of reaction products of Portland cement clinker and slag, is then used to predict the amounts of hydration products and the volume of pore solution.

The moles of alkalis in the pore solution $\left(n_{i}^{\mathrm{s}}\right)$ are computed with $V_{w}$ and $C_{i}$ with Eq. 8. Then, the moles of 
Fig. 3 Calculated molalities of alkalis in $\mathrm{C}-\mathrm{S}-\mathrm{H}$ according to Eq. 15 based on the experimental data of Longuet [5] and Schäfer [6]. The range of predicted $\mathrm{C} / \mathrm{S}$ ratios in $\mathrm{C}-\mathrm{S}-\mathrm{H}$ is also indicated

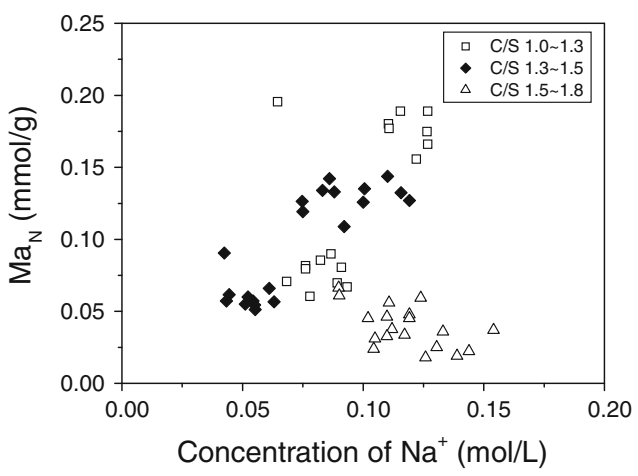

(a) $\mathrm{Na}^{+}$

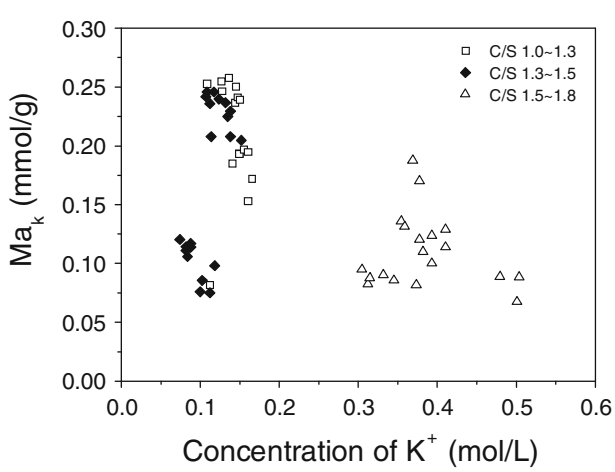

(b) $\mathrm{K}^{+}$ alkalis bound in the hydration products $\left(n_{i}^{\mathrm{b}}\right)$ are computed with Eq. 9.

It is hypothesized that the hydration product $\mathrm{C}-\mathrm{S}-\mathrm{H}$ is the main alkali-binding phase in the hydrated slag cement due to the fact that its amount is the largest in all the hydration products. The mass of $\mathrm{C}-\mathrm{S}-\mathrm{H}\left(m^{\mathrm{C}-\mathrm{S}-\mathrm{H}}\right)$ in the hydrated paste at different ages is predicted and the $M a_{i}$ of $\mathrm{C}-\mathrm{S}-\mathrm{H}$ is calculated as

$M a_{i}=\frac{n_{i}^{\mathrm{b}}}{m^{\mathrm{C}-\mathrm{S}-\mathrm{H}}}$

Results of the computation are plotted in Fig. 3. It appears that there are no obvious relationship between the molalities of alkali in the $\mathrm{C}-\mathrm{S}-\mathrm{H}$ and the alkali concentrations in the pore solution. Two factors most likely contribute to the obvious scattering in the figures. First, the $\mathrm{C}-\mathrm{S}-\mathrm{H}$ has various compositions, which has different alkali-binding capacities. Second, it is hypothesized in the computations that $\mathrm{C}-\mathrm{S}-\mathrm{H}$ is the only alkali binder, which needs to be verified.

The amount of alkalis bound in the hydration products $\left(n_{i}^{\mathrm{b}}\right)$ is also plotted against the mass of the hydrotalcitelike phase in Fig. 4 with slag cement $1-18$ in Table 3. Measurements obtained at ages longer than 68 days are used. A clear relationship between the amount of bound alkalis and the amount of the hydrotalcite-like phase is discerned. It is obvious that the inclusion of the hydrotalcite-like phase as the alkali binder is necessary when predicting the alkali concentrations in the pore solution.

However, the C-S-H gel cannot be neglected due to its dominant quantities in the hydrated paste and the amorphous nature of this product. Taking both the $\mathrm{C}-\mathrm{S}-\mathrm{H}$ gel and the hydrotalcite-like phase as the alkali binders in hydrated slag cement paste is thus reasonable. The mole of bound alkalis reads

$n_{i}^{\mathrm{b}}=M a_{i}^{\mathrm{C}-\mathrm{S}-\mathrm{H}} \cdot m^{\mathrm{C}-\mathrm{S}-\mathrm{H}}+M a_{i}^{\mathrm{HT}} \cdot m^{\mathrm{HT}}$

in which $M a_{i}^{\mathrm{C}-\mathrm{S}-\mathrm{H}}$ and $M a_{i}^{\mathrm{HT}}$ are the molalities of alkali $i$ in $\mathrm{C}-\mathrm{S}-\mathrm{H}$ and the hydrotalcite-like phase, respectively; $m^{\mathrm{HT}}$ is the mass of the hydrotalcite-like phase.
Define the distribution ratio of alkali $i\left(\mathrm{Na}^{+}\right.$or $\left.\mathrm{K}^{+}\right)$ as [8]

$\mathrm{Rd}=\frac{\text { alkali in hydration product }(\mathrm{mmol} / \mathrm{g})}{\text { alkali concentration in solution }(\mathrm{mmol} / \mathrm{mL})}$

(in $\mathrm{mL} / \mathrm{g}$ )

Therefore,

$M a_{i}=\mathrm{Rd}_{i} \cdot C_{i}$

Eq. 16 is then written as

$n_{i}^{\mathrm{b}}=\mathrm{Rd}_{i}^{\mathrm{C}-\mathrm{S}-\mathrm{H}} \cdot C_{i} \cdot m^{\mathrm{C}-\mathrm{S}-\mathrm{H}}+\mathrm{Rd}_{i}^{\mathrm{HT}} \cdot C_{i} \cdot m^{\mathrm{HT}}$

The experimental results on the alkali-binding capacity of $\mathrm{C}-\mathrm{S}-\mathrm{H}$ with various $\mathrm{C} / \mathrm{S}$ ratios by Hong and Glasser [9] are used to derive the alkali-binding capacity of the $\mathrm{C}-\mathrm{S}-\mathrm{H}$. The $\mathrm{C}-\mathrm{S}-\mathrm{H}$ was synthesized by using some mixed slurries of $\mathrm{Ca}(\mathrm{OH})_{2}$ and a very reactive, high surface area silica gel. A log-log plot of the measurements of $\mathrm{Rd}$ by Hong and Glasser [9] versus the $\mathrm{C} / \mathrm{S}$ ratios in the synthetic $\mathrm{C}-\mathrm{S}-\mathrm{H}$ gel is given in Fig. 5a and b. A linear relation is observed between the logarithm of $\mathrm{Rd}$ and that of the $\mathrm{C} / \mathrm{S}$ ratios. A comparison between the effects on $\mathrm{Na}^{+}$and $\mathrm{K}^{+}$ shows that the alkali-binding capacities of $\mathrm{C}-\mathrm{S}-\mathrm{H}$ are similar. The mean values of the slope coefficient in Fig. 5a and $b$ are -6.12 and -6.21 for $\mathrm{Na}^{+}$and $\mathrm{K}^{+}$, respectively.

Based on the relations shown in Fig. 5, it is proposed that the values of $\mathrm{Rd}_{i}^{\mathrm{C}-\mathrm{S}-\mathrm{H}}$ are related to the $\mathrm{C} / \mathrm{S}$ ratio of $\mathrm{C}-\mathrm{S}-\mathrm{H}$ as

$\mathrm{Rd}_{i}^{\mathrm{C}-\mathrm{S}-\mathrm{H}}=Y \cdot(\mathrm{C} / \mathrm{S})^{r}$

in which $Y$ is a characteristic coefficient $(\mathrm{mL} / \mathrm{g})$ and the values of $r$ are -6.12 and -6.21 for $\mathrm{Na}^{+}$and $\mathrm{K}^{+}$, respectively.

Constant values of $\mathrm{Rd}_{i}^{\mathrm{HT}}$ are used for the hydrotalcitelike phase. Substituting Eq. 20 into Eq. 19 gives:

$n_{i}^{\mathrm{b}}=Y \cdot(\mathrm{C} / \mathrm{S})^{r} \cdot C_{i} \cdot m^{\mathrm{C}-\mathrm{S}-\mathrm{H}}+\mathrm{Rd}_{i}^{\mathrm{HT}} \cdot C_{i} \cdot m^{\mathrm{HT}}$

A multiple linear regression analysis with the data presented in Figs. 4 and 5 yields the values of $Y, \mathrm{Rd}_{i}^{\mathrm{C}-\mathrm{S}-\mathrm{H}}$, $\mathrm{Rd}_{i}^{\mathrm{HT}}$, and $r$ (Table 4). Substituting typical values for the 
Fig. 4 Amount of bound alkali $\mathrm{Na}^{+}$and $\mathrm{K}^{+}$versus the mass of the hydrotalcite-like phase in the hydrated slag-blended cement pastes $1-18$ in Table 3

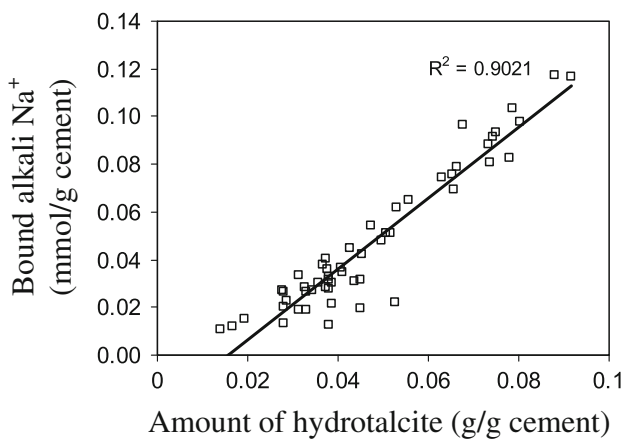

(a) $\mathrm{Na}^{+}$

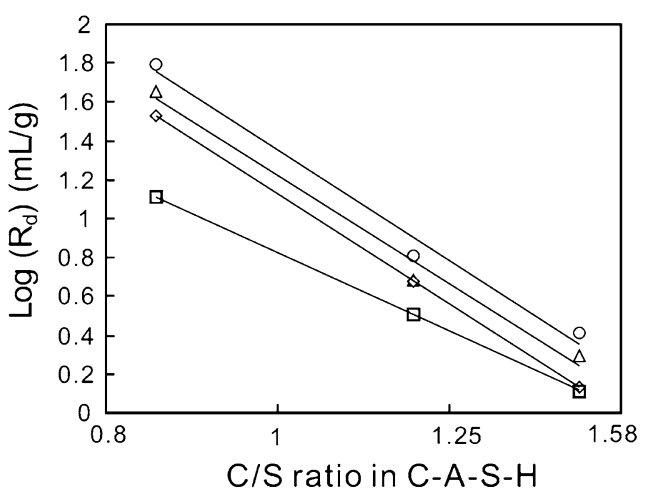

(a) $\mathrm{Na}^{+}$

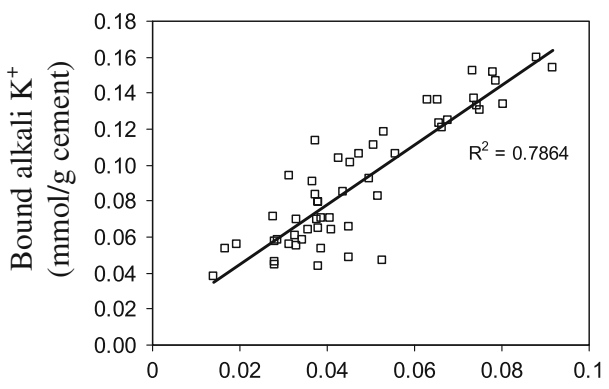

Amount of hydrotalcite ( $\mathrm{g} / \mathrm{g}$ cement)

(b) $\mathrm{K}^{+}$

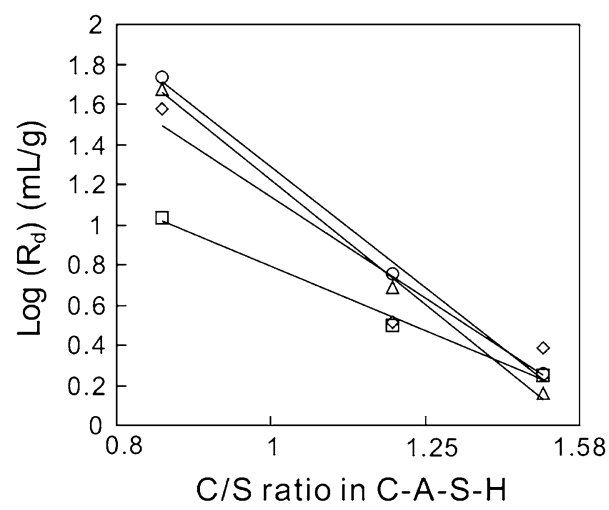

(b) $\mathrm{K}^{+}$
Fig. 5 Distribution ratio of alkalis in synthetic $\mathrm{C}-\mathrm{S}-\mathrm{H}$ gel versus its $\mathrm{C} / \mathrm{S}$ ratio, after Hong and Glasser [9]

$\circ 15 \mathrm{mmol} / \mathrm{L} \quad \Delta 50 \mathrm{mmol} / \mathrm{L} \diamond 100 \mathrm{mmol} / \mathrm{L} \quad \square 300 \mathrm{mmol} / \mathrm{L}$

Table 4 Fitted values of $Y, \mathrm{Rd}^{\mathrm{C}-\mathrm{S}-\mathrm{H}}$ and $\mathrm{Rd}^{\mathrm{HT}}$ for $\mathrm{Na}^{+}$and $\mathrm{K}^{+}$with multiple linear regression analysis, together with the values of $r$

\begin{tabular}{|c|c|c|c|c|c|c|}
\hline \multirow[t]{2}{*}{ Alkali } & \multirow[t]{2}{*}{$Y(\mathrm{~mL} / \mathrm{g})$} & \multirow[t]{2}{*}{$r$} & \multicolumn{2}{|c|}{$\mathrm{Rd}^{\mathrm{C}-\mathrm{S}-\mathrm{H}}(\mathrm{mL} / \mathrm{g})$} & \multirow{2}{*}{$\begin{array}{l}\mathrm{Rd}^{\mathrm{HT}} \\
(\mathrm{mL} / \mathrm{g})\end{array}$} & \multirow[t]{2}{*}{$R^{2}$} \\
\hline & & & $\mathrm{C} / \mathrm{S}=1.1$ & $\mathrm{C} / \mathrm{S}=1.8$ & & \\
\hline $\mathrm{Na}^{+}$ & 0.1 & -6.12 & 0.056 & 0.0027 & 9.6 & 0.62 \\
\hline $\mathrm{K}^{+}$ & 0.23 & -6.21 & 0.13 & 0.0059 & 10.2 & 0.56 \\
\hline
\end{tabular}

$\mathrm{C} / \mathrm{S}$ ratio of $\mathrm{C}-\mathrm{S}-\mathrm{H}$ in hydrated slag cement (for example, 1.1 and 1.8) into Eq. 20 yields the values for $\mathrm{Rd}_{\mathrm{Na}}^{\mathrm{C}-\mathrm{S}-\mathrm{H}}$ and $\mathrm{Rd}_{\mathrm{K}}^{\mathrm{C}-\mathrm{S}-\mathrm{H}}$ as listed in Table 4.

Based on the commuted results presented in Table 4, the hydrotalcite-like phase has a much stronger alkali-binding capacity than the $\mathrm{C}-\mathrm{S}-\mathrm{H}$ in hydrated slag cement paste. The $\mathrm{C}-\mathrm{S}-\mathrm{H}$ in hydrated slag cement pastes shows relatively weakened alkali-binding capacity as compared to that in hydrated Portland cement pastes $[2,3,16]$. As the $\mathrm{C}-\mathrm{S}-\mathrm{H}$ in hydrated slag cement paste contains higher content of aluminum in the structure than the $\mathrm{C}-\mathrm{S}-\mathrm{H}$ in hydrated Portland cement paste [7], it appears that the incorporation of aluminum into $\mathrm{C}-\mathrm{S}-\mathrm{H}$ changes the alkalibinding capacity drastically.

\section{Predicting the alkali concentrations}

The alkali concentrations in the pore solution of hydrated slag cement paste can be predicted if the moles of alkalis released by the cement hydration $\left(n_{i}^{\mathrm{r}}\right)$ and those bound in the solids $\left(n_{i}^{\mathrm{b}}\right)$ are known. Substituting Eq. 21 into Eq. 13 gives

$$
n_{i}^{\mathrm{r}}=Y \cdot(\mathrm{C} / \mathrm{S})^{r} \cdot C_{i} \cdot m^{\mathrm{C}-\mathrm{S}-\mathrm{H}}+R d_{i}^{\mathrm{HT}} \cdot C_{i} \cdot m^{\mathrm{HT}}+C_{i} \cdot V_{w}
$$

The concentration of alkali $i$ is the only unknown in Eq. 22 and can thus be solved with numerical methods.

The method for predicting the alkali concentrations in hydrated slag cement pastes is validated with the experimental data from the work of Longuet [5]. The $w / c$ ratio was 0.5 and the paste samples were cured at $20^{\circ} \mathrm{C}$ in a sealed environment. The paste contained $19.1 \mathrm{~m} / \mathrm{m} \%$ of $\mathrm{C} 1,4.5 \mathrm{~m} / \mathrm{m} \%$ gypsum, and $76.4 \mathrm{~m} / \mathrm{m} \%$ S2 (Recipe 4 in Table 3). The pore solution was collected by the compression method at different ages. The alkali concentrations predicted with the methods established in this study are plotted in Fig. 6. It can be seen that the predicted alkali concentrations in the pore solution agree well with the measurements in experiments by using the proposed 


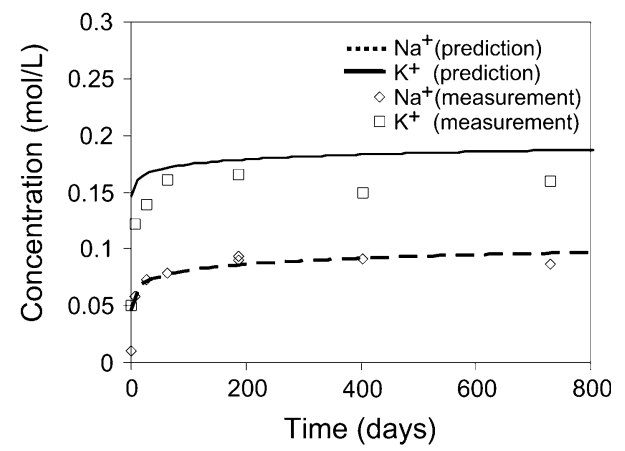

Fig. 6 Predicted and measured alkali concentrations in the pore solution of the hydrated slag cement paste with Recipe 4 in Table 3 (experimental data: Longuet [5])

method. It is noted that during the validation process above, no specific calibrations were made.

The alkali-binding capacities of the hydration products investigated in this study are derived from a large set of experimental results with 18 different recipes involving three types of clinker and seven types of slag. The large volume of data and complexity of the experimental design assure the validities of the quantitative models developed for determining the alkali-binding capacities of the hydrotalcite-like phase and the $\mathrm{C}-\mathrm{S}-\mathrm{H}$. It is noteworthy that experimental results from other references can be similarly used for this purpose when they are available, which will add to the creditability of the extended methods developed in this study.

\section{Applications of the method}

Numerous researches have been done to investigate the pore solution development in hydrated Portland cement and slag cement pastes and efforts are made to clarify the effect of different factors on the pore solution compositions. In this section, the effects of these factors on the alkali concentration in the pore solution of hydrated slag cement pastes are discussed with the method developed in this study.

Combinations of clinker $\mathrm{C} 2$ and slag S5 taken from the study of Schäfer [6] are used as examples. The compositions of the Portland clinker and slag are listed in Table 2. Cement pastes with different recipes are investigated. The hydration age is taken to be 1 year since this will give an adequate base for evaluating the long-term properties, for example, the likelihood of the alkali-silica reaction (ASR).

Effect of slag proportion on the alkali concentrations

Schäfer investigated the effect of slag proportion on the alkali concentrations and found that the concentrations decrease with increasing slag proportions in the paste [6]. The method established in this study is used to simulate the development of alkali concentrations in the pore solution of hydrated slag cement paste with different slag proportions and the predictions are plotted in Fig. 7 together with the measurement. The predictions agree well again with the measurements.

The lowering effect of increasing slag proportion on the alkali concentrations is due to at least three factors. First, higher slag proportions result in more unreacted slag in the paste, reducing the amount of alkalis available for the pore solution (the dilution effect). Second, the volume of water available for the pore solution is even bigger for higher slag proportions due to the smaller amount of hydration products. Third, the amount of the hydrotalcite-like phase increases with high slag proportions, which is able to bind more alkalis. Hence, high slag proportions in the blended cement are preferential in regard to lowering the alkali concentrations in the pore solution.
Fig. 7 Effect of slag proportion on the alkali concentrations in pore solution of slag cement paste (C2 and S5; numbers in the legend indicate the slag proportion in the cement; experimental data: [6])

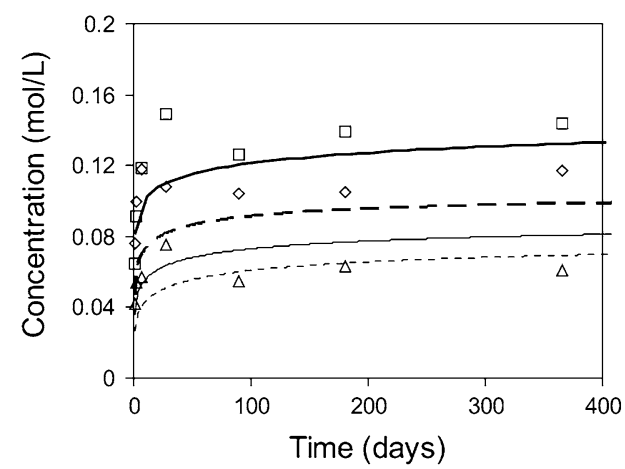

(a) $\mathrm{Na}^{+}$

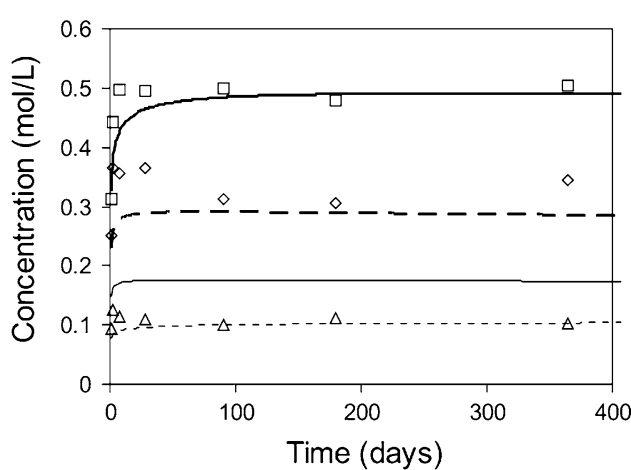

(b) $\mathrm{K}^{+}$

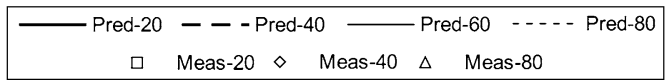




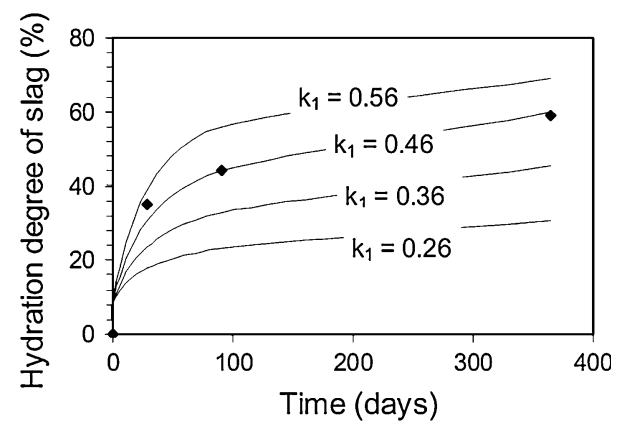

Fig. 8 Simulated hydration degree of slag in cement paste with different slag reactivities. $w / c=0.5, \mathrm{C} 2$ and S5 are used. Symbol closed diamond represents the measured data by Schäfer [6]. $k_{1}$ is the parameter used for determining the hydration degree of slag

\section{Effect of slag reactivity on the alkali concentrations}

High reactivity of slag is normally preferred in practice with respect to the strength development of the concrete. Hence, the reactivity of slag is regulated in the various norms by some indices or results of strength tests. The influence of slag reactivity is investigated in this study by using the proposed methods as well.

Cement pastes with $40 \mathrm{~m} / \mathrm{m} \%$ slag replacement are used, with a $w / c$ ratio of 0.5 . The different slag reactivities are simulated by changing the factor $k_{1}$ in Table 1 . Beside the value 0.46 recommended by Taylor [2], two other values are used as well. The simulated hydration degree of slag with different slag reactivities are presented in Fig. 8. The simulated hydration degrees of slag are $56.8 \%, 63.3 \%$, $69.8 \%$, and $76.1 \%$ after 1 year hydration, respectively. Predictions are plotted in Fig. 9 together with the measurements in experiments. It can be seen that the alkali concentrations in the pore solution is not significantly influenced by the slag reactivity in cement.

This mild effect of the slag reactivity on the alkali concentrations in the pore solution could be explained with interactions of three major factors. If more slag has reacted at the given age, corresponding to slag with a higher reactivity, more alkalis are released and become available for the solution. Furthermore, with more water bound in the hydration products, the volume of the pore solution is reduced and the alkalis in the solution are concentrated. The consequence of the above two factors is the raise of alkali concentrations in the solution. However, if more hydration products $\mathrm{C}-\mathrm{S}-\mathrm{H}$ and the hydrotalcite-like phase are formed by the slag reaction, which is able to bind more alkalis, the alkali concentrations in the solution is reduced. The net result of this two counteracting effects is the mild change of alkali concentrations in the solution.

The influence of the slag reactivity on the alkali concentrations is much more limited compared to the influence of slag proportions (Fig. 7). Hence, the slag hydration degree does not appear to be essential with respect to the alkali concentrations in the pore solution.

Effect of alkali distribution in clinker and in slag on the alkali concentrations

There are primarily two sources of alkali ions in hydrated slag cement, the clinker and slag. Alkalis from these two sources are generally not distinguished when the risk of alkali silica reaction or alkali carbonate reaction is evaluated. However, alkalis from the clinker and the slag are released at different rates.

Hence, the influence of different distribution of alkalis in slag-blended cement between the clinker and slag on the alkali concentration is investigated with the method established in this study, Recipe 10 listed in Table 3 is used. The alkali level of the slag cement is raised in two ways by increasing the $\mathrm{Na}_{2} \mathrm{O}$ or $\mathrm{K}_{2} \mathrm{O}$ in slag or in cement, respectively. Four alkali levels are used, which are listed in Table 5. The added alkalis to the original recipe are always $0.3 \mathrm{~m} / \mathrm{m} \%$ (as $\mathrm{Na}_{2} \mathrm{O}_{\mathrm{eq}}$ ). The simulated alkali concentrations in the pore solution are plotted in Fig. 10.

It can be seen that for both $\mathrm{Na}^{+}$and $\mathrm{K}^{+}$, an increase in the alkali content in the clinker results in much higher
Fig. 9 Effect of slag reactivity on the alkali concentrations in pore solution of hydrated slag cement (Recipe 10 in Table 2). $a, b, c$, and $d$ correspond to the different values of $k_{1}$ used for predicting the slag reactivities, i.e., 0.26, 0.36, 0.46, 0.56, respectively. The measurements are taken from Schäfer [6]

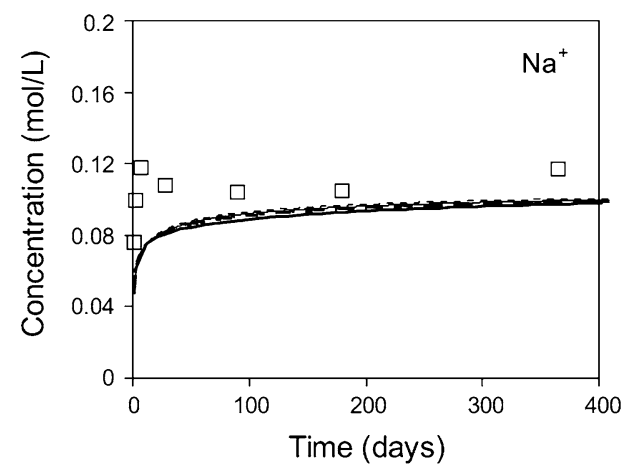

(a) $\mathrm{Na}^{+}$

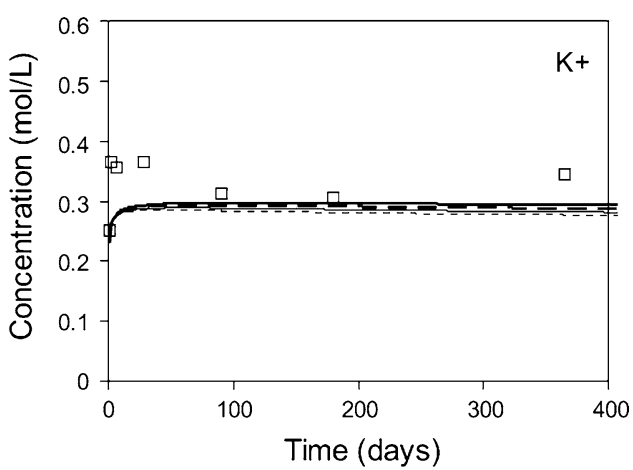

(b) $\mathrm{K}^{+}$

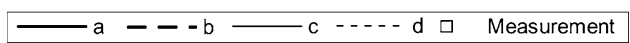


Table 5 Alkali levels in slag and clinker modified from the work of Schäfer [6] $(\mathrm{m} / \mathrm{m} \%)$

\begin{tabular}{lllllll}
\hline Material & Oxide & \multicolumn{2}{l}{ Recipe } \\
\cline { 3 - 7 } & & Original $^{\mathrm{a}}$ & 1 & 2 & 3 & 4 \\
\hline Clinker & $\mathrm{Na}_{2} \mathrm{O}$ & 0.14 & 0.44 & 0.14 & 0.14 & 0.14 \\
& $\mathrm{~K}_{2} \mathrm{O}$ & 0.95 & 0.95 & 1.4 & 0.95 & 0.95 \\
\multirow{3}{*}{ Slag } & $\mathrm{Na}_{2} \mathrm{O}$ & 0.29 & 0.29 & 0.29 & 0.59 & 0.29 \\
& $\mathrm{~K}_{2} \mathrm{O}$ & 0.38 & 0.38 & 0.38 & 0.38 & 0.835
\end{tabular}

${ }^{a}$ Original levels in the work of Schäfer [6]

concentrations than an increase in that of the slag. An increase of alkalis in slag yields only a slight increase of alkali concentrations in the pore solution, to a less extent for $\mathrm{K}^{+}$than for $\mathrm{Na}^{+}$. The main reason for this difference is the relatively low hydration degree of slag in the paste, which reduces the total amount of alkalis released. In other words, a part of the alkalis in the slag remains encapsulated in the unreacted slag. Hence, the alkali level in the cement clinker used in slag cement deserves special attention because it is more important than that of slag.

\section{Discussions}

The alkali-binding capacity of $\mathrm{C}-\mathrm{S}-\mathrm{H}$ in hydrated slag cement paste is much lower than of in hydrated Portland cement paste $[2,3,16]$. A possible explanation could be that the $\mathrm{C}-\mathrm{S}-\mathrm{H}$ in hydrated slag cement paste contains much more aluminum in its structure compared to that in hydrated Portland cement paste [7]. It was found in the experiments of Stade that the $\mathrm{Al}$ containing $\mathrm{C}-\mathrm{S}-\mathrm{H}$ has weaker alkali-binding capacity than the Al-free one [10], which is contrary to the conclusions of Hong and Glasser [9]. The contrary conclusions about the role of alumina substitution in $\mathrm{C}-\mathrm{S}-\mathrm{H}$ on its alkali-binding capacity could be partly due to the alumina substitution level. The aluminum to silica molar ratio $(\mathrm{A} / \mathrm{S})$ used by Hong and
Glasser [9] is about 0.031-0.038, while that used by Stade [10] is 0.07 , the latter being more close to the actual values measured in the hydrated slag cement pastes [7].

The weak alkali-binding capacity of $\mathrm{C}-\mathrm{S}-\mathrm{H}$ in hydrated slag cement is partly proved in the experiments of Schäfer [6] as well. Schäfer measured the alkali concentrations in hydrated slag cement pastes with different proportions of slag. If $20 \mathrm{~m} / \mathrm{m} \%$ the Portland cement is replaced by slag, the $\mathrm{Na}^{+}$concentration is even higher than that of the neat Portland cement. While the addition of slag is known to reduce the $\mathrm{C} / \mathrm{S}$ ratio in $\mathrm{C}-\mathrm{S}-\mathrm{H}$ and dilute the amount of alkalis in cement, both being beneficial for lowering the alkali concentrations in the pore solution, the measured concentrations are even higher. Similar trends are observed in the experiments of Kollek et al. [17]. A $20 \mathrm{~m} / \mathrm{m} \%$ replacement of Portland cement by slag was found unable to significantly reduce the hydroxyl concentration. The hydroxyl concentration is increased in three pastes.

Apparently, the alkali-binding capacity of $\mathrm{C}-\mathrm{S}-\mathrm{H}$ changes dramatically when part of the Portland cement clinker is replaced by slag. The reasons for this change are not clear yet. The measured concentrations of $\mathrm{Na}^{+}$and $\mathrm{K}^{+}$ are distributed in small ranges $\left(0.05-0.15 \mathrm{mmol} / \mathrm{L}\right.$ for $\mathrm{Na}^{+}$ and $0.1-0.4 \mathrm{mmol} / \mathrm{L}$ for $\mathrm{K}^{+}$), as compared to those in hydrated Portland cement pastes. Thus, it is difficult to investigate the influence of the alkali concentrations on binding as such and hence, to examine possible nonlinear absorption characteristics.

\section{Conclusion}

An extended method for predicting the alkali concentrations in the pore solution of hydrated slag cement paste is established based on the alkali partition theory. The main emphasis is put to clarify the alkali-binding capacities of hydration products. The following conclusions are drawn based on the investigations and discussions presented in this study:
Fig. 10 Effect of the alkali distribution in cement on the alkali concentrations, predicted with Recipe 10 in Table 3, $w / c=0.5, T=20^{\circ} \mathrm{C}$. " $1 ", " 2 "$, etc. correspond to the recipes in Table 5

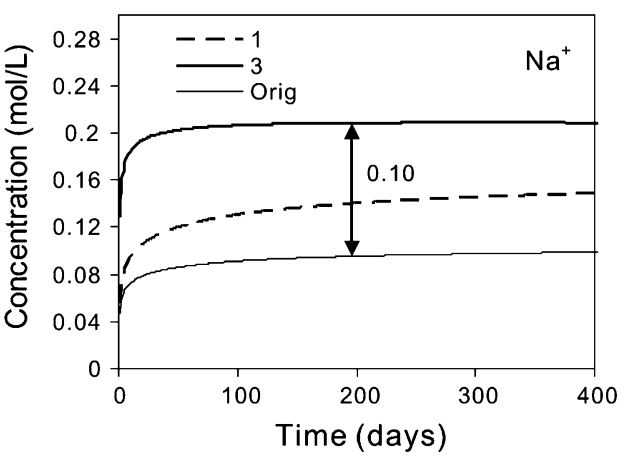

(a) $\mathrm{Na}^{+}$

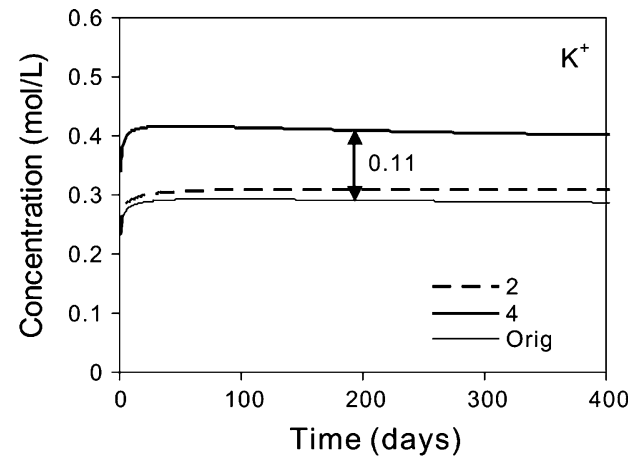

(b) $\mathrm{K}^{+}$ 
1. Both the $\mathrm{C}-\mathrm{S}-\mathrm{H}$ and the hydrotalcite-like phase can bind alkalis in the hydrated slag cement pastes. The alkali-binding capacity of the individual product is derived from a large set of experimental data. The hydrotalcite-like phase particularly shows a strong alkali-binding capacity. Incorporation of aluminum into the structure of $\mathrm{C}-\mathrm{S}-\mathrm{H}$, which generally takes place in hydrated slag cement paste, weakens the alkali-binding capacity of $\mathrm{C}-\mathrm{S}-\mathrm{H}$.

2. The alkali concentrations are obviously influenced by the slag proportions in the cement. The slag reactivity does not influence the alkali concentrations in the pore solution significantly, if the alkali level in the slag and clinker is comparable.

3. An increase in the alkali content in the clinker results in much higher concentrations than an increase in that of the slag. An increase of alkalis in slag yields only a slight increase of alkali concentrations in the pore solution, to a less extent for $\mathrm{K}^{+}$than for $\mathrm{Na}^{+}$. There is no significant difference between the $\mathrm{Na}_{2} \mathrm{O}$ and $\mathrm{K}_{2} \mathrm{O}$ when the additional amount of alkali presents in the clinker.

Acknowledgements The authors wish to thank the following institutions for their financial support of the present research: Dr. ir. Cornelis Lely Foundation, Delta Marine Consultants, Bouwdienst Rijkswaterstaat, Rokramix, SenterNovem Soil+, Jaartsveld Groen en Milieu, Betoncentrale Twenthe, Graniet-Import Benelux, Kijlstra Beton, Struyk Verwo Groep, Hülskens, Insulinde, Dusseldorp Groep, Eerland Recycling, Enci, Provincie Overijssel, Rijkswaterstaat Directie Zeeland, A\&G Maasvlakte, BTE, Alvon Bouwsystemen, v. d. Bosch Beton, the National Natural Science Foundation of China (Project 50802067), the Scientific Research Foundation for the Returned Overseas Chinese Scholars, Ministry of Education and the
Fundamental Research Funds for the Central Universities (project 2010-VI-011).

Open Access This article is distributed under the terms of the Creative Commons Attribution Noncommercial License which permits any noncommercial use, distribution, and reproduction in any medium, provided the original author(s) and source are credited.

\section{References}

1. Longuet P, Burglen L, Zelwer A (1973) Revue des Matériaux de Construction 676:35

2. Taylor HFW (1987) Adv Cement Res 1:5

3. Brouwers HJH, Van Eijk RJ (2003) Cem Concr Res 33:191

4. Bentz DP (1997) J Am Ceram Soc 80:3

5. Longuet $P$ (1976) Silic Ind 7(8):321

6. Schäfer E (2004) PhD thesis, Clausthal University of Technology, Clausthal-Zellerfeld, Germany

7. Richardson IG, Groves GW (1992) J Mater Sci 27:6204. doi: 10.1007/BF01133772

8. Hong SY, Glasser FP (1999) Cem Concr Res 29:1893

9. Hong SY, Glasser FP (2002) Cem Concr Res 32:1101

10. Stade H (1989) Cem Concr Res 19:802

11. Chen W, Brouwers HJH (2007) J Mater Sci 42:444. doi:10.1007/ s10853-006-0874-1

12. Bentz DP (2000) CEMHYD3D: a three-dimensional cement hydration and microstructure development modelling package, version 2.0. Tech. Rep. NISTIR 6485, NIST, Gaithersburg, US

13. Van Breugel K (1997) Cem Concr Res 34:1661

14. Chen W, Brouwers HJH (2007) J Mater Sci 42:428. doi:10.1007/ s10853-006-0873-2

15. Duan X, Evans DG (2006) Layered double hydroxides. Springer, Berlin

16. Chen W, Brouwers HJH (2010) Cem Concr Res 40:716

17. Kollek JJ, Varma SP, Zaris C (1986) In: Proceedings of 8th ICCC, vol 4. Rio de Janeiro, pp 183-189 